\title{
Memória e des-memória discursivas no movimento ciberfeminista
}

\section{Julia Lourenço Costa}

Pesquisadora pós-doutorado da Universidade Federal de São Carlos (UFSCar), Brasil. Processo FAPESP número 2017/12792-0.

juliajlc@gmail.com

Resumo: O movimento feminista tem ganhado cada vez mais força no ciberespaço, onde o chamado ciberfeminismo (PLANT, 1992) vem se apropriando das ferramentas virtuais disponíveis. A hashtag, enquanto tecnopalavra (PAVEAU, 2017) funciona no ciberativismo enquanto ponto de ancoragem do debate público acerca de determinada temática. $O$ tema do assédio, que faz parte da agenda feminista (HIRATA et al., 2009) será discursivamente analisado a partir da irrupção e circulação da hashtag \#metoo, que tomou as redes sociais no final de 2017. Ancorados na Análise do discurso francesa, o corpus será analisado mobilizando as noções de memória e des-memória discursivas (PAVEAU, 2013; 2013a; 2015; 2017) na medida em que sua mobilização instaura a polêmica como interincompreensão (MAINGUENEAU, 2008), gerando uma espécie de dissenso, manifestado a partir de diversas posições enunciativas.

Palavras-chave: Ciberfeminismo. Memória discursiva. Des-memória discursiva. Polêmica.

Abstract: The feminist movement has gained more strength in cyberspace, where the socalled cyberfeminism (PLANT, 1992) has appropriated the available virtual tools. The hashtag, while techno-word (PAVEAU, 2017) functions in cyberactivism as the anchoring point of the public debate about a certain theme. The issue of harassment, which is part of the feminist agenda (HIRATA et al., 2009) will be discursively analyzed from the irruption and circulation of the hashtag \#metoo, which took social network at the end of 2017. Anchored in the French Discourse Analysis, the corpus will be analyzed by mobilizing the notions of discursive memory and des-memory (PAVEAU, 2013, 2013a, 2015, 2017), inasmuch as it establishes the polemic as interincomprehension (MAINGUENEAU, 2008), generating a kind of dissent, manifested from different enunciative positions.

Keywords: Cyberfeminism. Discursive memory. Discursive des-memory. Polemics. 


\section{$\mathrm{EI} \square \mathrm{dA}$}

\section{Primeiras palavras: o ciberespaço em foco}

A partir da concepção do ciberespaço como "novo meio de comunicação que surge da interconexão mundial de computadores" (LÉVY, 1999, p. 17) pretendemos neste trabalho refletir sobre o ativismo que se consolida neste espaço de interação social, definido pela troca virtual simbólica. Nosso olhar científico-analítico incidirá especificamente na constituição, consolidação e circulação dos discursos que se inserem no chamado movimento ciberfeminista.

A internet, de acordo com o referido autor, é um dos principais novos meios de comunicação, sendo encarada como parte das tecnologias digitais e funcionado enquanto infraestrutura das comunicações no ciberespaço. Nela, são criados diversos ambientes virtuais de interação, que reconstroem as relações intersubjetivas, agora mediadas pela máquina.

O ciberespaço estabelece, dentre outras características, nova relação com o tempo e com o espaço, além da própria reformulação da interação intersubjetiva. O sujeito, já antes concebido como heterogêneo, extrapola na internet sua constituição plural e dialógica, ao mesmo tempo em que sua busca de pertencimento à determinada comunidade se torna mais incessante.

Os movimentos sociais têm cada vez mais ganhado força de circulação no ciberespaço, que funciona como amplificador online das causas já debatidas offline. O poder da internet está, em certa medida, relacionado à capacidade do comportamento humano de se refletir no ambiente virtual, daí o surgimento do termo cibercultura, como relação entre sociedade, cultura e ambiente eletrônico virtual. Segundo Lévy,

[...] é impossível separar o humano de seu ambiente material, assim como dos signos e das imagens por meio dos quais ele atribui sentido à vida e ao mundo. Da mesma forma, não podemos separar o mundo material - e menos ainda sua parte artificial - das ideias por meio das quais os objetos técnicos são concebidos e utilizados, nem dos humanos que os inventam, produzem e utilizam [...] (LÉVY, 1999, p. 21).

$\mathrm{Na}$ internet, diversas instituições discursivas produzem e circulam sentido e, se verifica, contemporaneamente, a proliferação das manifestações relacionadas aos movimentos sociais que - assim como a própria sociedade estão em constante transformação. O ciberativismo, como processo de adaptação dos movimentos sociais às novas tecnologias, tem contribuído não 
só na divulgação das variadas causas sociais, políticas e econômicas, mas na própria determinação destes movimentos reivindicatórios.

De acordo com Castells (2001), as lutas sociais foram historicamente marcadas por movimentos sociais que mantinham certa cadeia hierárquica alinhada aos valores verticalizados do processo de industrialização. Por outro lado, o que se assiste hoje com o ciberativismo, é a horizontalização das lutas contemporâneas, que passam a ter uma estrutura marcada pelo acesso mais democrático proporcionado pela rede.

A internet se configura como ferramenta para as lutas sociais contemporâneas e é concebida como espaço potencial de expressão e participação genuinamente democrática ${ }^{1}$ (DEIBERT, 2000). Tal ferramenta viabiliza a união e a mobilização das variadas comunidades discursivas ${ }^{2}$, além da promoção horizontalizada das informações, que passam a ser difundidas de lugares discursivos cada vez menos marcados pela hierarquia das relações sociais.

\section{Feminismo em rede: ciberfeminismo}

O ciberfeminismo se desenvolveu a partir da década de 1990, juntamente com o surgimento das primeiras redes de computadores. Ele emerge como reinvenção de outros movimentos feministas, a partir de uma abordagem das tecnologias de comunicação. $O$ ciberfeminismo se desenvolveu na esteira do conceito de pós-feminismo que:

\footnotetext{
1 “Com relação aos prós e contras dessa apropriação social da técnica, as opiniões estão divididas. Como demonstra Deibert (2000), a posição otimista sustentada por teóricos de influência Gramsciana (COX, 1999) e Liberal (FALK, 1992; 1995), acredita que as redes de cidadãos constituem uma potencial expressão de participação genuinamente democrática, nas arenas até então monopolizadas pelo Estado e por corporações transnacionais; sendo que a Internet é considerada essencial para que essas redes se desenvolvam (p.256) Por outro lado, há teóricos que sustentam o argumento de que, longe de se tornarem uma expressão da democracia, essas redes de cidadãos baseadas na Internet conduzem a uma ruína democrática em escala global; pelo fato de permitirem que muitos interesses diferentes ou, até mesmo contraditórios, sejam discutidos em nível internacional sem nunca se alcançar nenhuma meta - mas causando um enorme "engarrafamento" de idéias, posições e visões de mundo - nem sempre positivas (RIEFF, CLOUGH apud DEIBERT, 2000, p. 256). Além disso, existem outros autores que defendem que as verdadeiras ações coletivas estão baseadas em relações face-a-face, sendo que a partir da Internet não é possível obterem sucesso (TARROW, 2002)" (RIGITANO, 2003).

2 "Na problemática de Maingueneau, $(1984,1987)$, a noção de comunidade discursiva é solidária à de formação discursiva. Efetivamente, a hipótese subjacente é que não basta opor as formações discursivas em termos puramente textuais: de um discurso a outro, "há mudança na estrutura e no funcionamento dos grupos que gerem esses discursos" (1984:135). Em outros termos, os modos de organização dos homens e de seus discursos são indissociáveis; as doutrinas são inseparáveis das instituições que as fazem emergir e que as mantêm" (MAINGUENEAU; CHARAUDEAU, 2008, p. 108).
} 
[o conceito de pós-feminismo] poderá assim traduzir a existência hoje de uma multiplicidade de feminismos, ou de um feminismo "plural", que reconhece o fator da diferença como uma recusa da hegemonia de um tipo de feminismo sobre outro, sem contudo pretender fazer tabula rasa das batalhas ganhas, nem reificar ou "fetichizar" o próprio conceito de diferença (HIRATA et al., 2009, p. 153-154).

Com base nas teorias acerca do pós-humanismo ${ }^{3}$, o ciberfeminismo pode ser compreendido como nova manifestação dentro dos movimentos feministas. Com característica multifacetada e polifônica, o ciberfeminismo procura agrupar as diversas manifestações de variados atores sociais, que têm como ponto comum o reconhecimento das diferenças de poder entre homens e mulheres, e que, portanto luta pela equidade entre os gêneros.

Donna Haraway (1984), inspiradora do movimento ciberfeminista, reconhece que é difícil nomear um movimento tão multiforme, afirmando que "a consciência da exclusão que é produzida por meio do ato da nomeação é aguda. As identidades parecem contraditórias, parciais e estratégicas". (HARAWAY, 1984, p. 47). A autora defende o pluralismo identitário que permeia todos, não somente as mulheres.

O ciberfeminismo, a partir do ambiente virtual, procura, então, quebrar paradigmas reais, uma vez que "o ciberfeminismo é político, e não uma desculpa para a falta de ação no mundo real, e é inclusivo e respeitável em relação às muitas culturas que as mulheres habitam" (HAWTHORNE; KLEIN, 1999, p. 2).

O feminismo em rede, apesar de se constituir enquanto movimento heterogêneo, mantém um núcleo comum, determinado pela defesa da identidade e do papel social da mulher segundo novos paradigmas. Ele emerge a partir do "esforço e da importância de estabelecer uma rede de comunicação entre as mulheres" (COLLADO; NAVARRETE, 2006), uma vez que é a partir do debate, do diálogo e da circulação das ideias que os movimentos sociais tomam forma e se fortalecem.

Ainda de acordo com as autoras, o ciberfeminismo pode ser definido como "prática feminista em rede, que tem por intuito, tanto politicamente,

\footnotetext{
3 “Segundo Dyens (2001, pp. 2-3), nossos corpos são agora feitos de máquinas, imagens e informações. Os corpos vivos estão borrados, moldados e transformados pela tecnologia e a cultura está tomando conta da biosfera. Do mesmo modo, Hayles (1996, p. 12) considera que o póshumano representa a construção do corpo como parte de um circuito integrado de informação e matéria que inclui componentes humanos e não-humanos, tanto chips de silício quanto tecidos orgânicos, bits de informação e bits de carne e osso. Um tal recorte semântico, pressagiando o futuro de uma outra espécie de corpo, nas interfaces do humano e do maquínico, é aquele que, sem dúvida, tem dominado no entendimento do pós-humano" (SANTAELLA, 2007, p. 130).
} 
quanto esteticamente, a construção de novas ordens e desmontagem de velhos mitos da sociedade através do uso da tecnologia" (COLLADO; NAVARRETE, 2006).

O desenvolvimento e utilização de novas tecnologias esteve, tradicionalmente, sob o domínio masculino, pois, histórico-culturalmente está designado ao homem o direito de ocupação do espaço público. A reivindicação e empenho das mulheres em ocupar se aproprias das novas tecnologias é uma das formas de ativismo feminista, pois se trata de lhes dar voz através dos meios de comunicação contemporâneos, dentre eles, principalmente, a internet.

Uma das manifestações do pós-feminismo é o próprio ciberfeminismo, determinado pela ocupação das mulheres dos espaços sociais, doravante redesenhados pelo espaço da web. Os ideais feministas, mantidos em sua essência, procuram, portanto, ser preservados no espaço virtual, no qual cada vez mais as mulheres têm, não só se manifestado de modo passivo utilizando as ferramentas já disponíveis -, mas de modo ativo (atuando cada vez mais na área de tecnologia e informática $)^{4}$.

\section{2. $O$ assédio sexual na agenda feminista}

O espaço virtual exacerba o caráter já heterogêneo do movimento feminista e, cada vez mais, fala-se em feminismos - no plural. De acordo com Hirata et al. (2009) é possível afirmar que o fator de unificação do feminismo reside na centralidade observada na problemática da dominação entre os sexos e suas consequências. De modo geral, a reivindicação por uma sociedade mais igualitária entre homens e mulheres é o tema central da agenda feminista.

Tal temática principal se decompõem em subtemas relacionados, tais como as questões em torno do corpo feminino (que envolvem desde a liberdade de escolha do vestuário até a descriminalização do aborto); a relação entre cidadania e gênero; as diferenças biológicas e as implicações na ascensão profissional no mercado de trabalho; a disparidade na dedicação ao trabalho doméstico; a desigualdade na educação e socialização; os vestígios do patriarcado; a violência contra a mulher, etc.

\footnotetext{
${ }^{4}$ Existe diversos grupos em todo o mundo que discutem a relação da mulher com a criação e gerenciamento de novas tecnologias. Citamos alguns: Rail Girls, Women who code, PyLadies, Code Girls, MariaLab, Women TechMakers, Womoz, Meninas Digitais, Mulheres na tecnologia, Technovation, dentre outros.
} 
Dentre os temas que fazem parte do escopo traçado pelo feminismo encontra-se o assédio, que pode ser definido como "condutas de natureza sexual, quer sejam de expressão física, verbal ou não-verbal, propostas ou impostas a pessoas contra sua vontade [...], e que acarretam um ataque à sua dignidade (HIRATA et al. 2009, p. 26).

Neste artigo, nosso olhar incidirá sobre o assédio sofrido por mulheres na relação direta com o desenvolvimento profissional. De acordo com Rago (1997) "os direitos de utilização dos corpos das mulheres, aí compreendidos evidentemente em sua dimensão sexual, foram perpetuados no seio das relações salariais". Pretendemos refletir sobre a temática do assédio, na medida em que ela afeta diretamente as mulheres não só no espaço privado ou público, mas também no ambiente profissional.

O processo mais amplo de inserção das mulheres no mercado de trabalho ocorreu principalmente durante as grandes guerras mundiais momentos nos quais a figura feminina esteve fortemente relacionada ao empoderamento. Porém, os altos cargos continuavam sendo ocupados majoritariamente por homens, fato que, da perspectiva salarial e da ascensão profissional, determinavam à figura da mulher enquanto corpo a ser negociado.

A noção de assédio sexual foi desenvolvida por feministas da Universidade de Cornell nos anos 70, a partir da observação das práticas no contexto das relações de trabalho. No campo jurídico, o assédio sexual é definido no artigo 216-A da Constituição como:

Ato de constranger alguém com o intuito de obter vantagem ou favorecimento sexual, prevalecendo-se o agente da sua condição de superior hierárquico ou ascendência inerentes ao exercício do emprego, cargo ou função (BRASIL, 2001).

Apesar do assédio sexual poder atingir homens e mulheres, estas, segundo FACURI (2013) são as principais vítimas. De acordo com o Datafolha Instituto de pesquisas, $42 \%$ das mulheres brasileiras já sofreram assédio sexual. Ainda segundo a pesquisa, $22 \%$ das mulheres já sofreu algum tipo de assédio no transporte público; $15 \%$ assédio no trabalho; $10 \%$ foram assediadas sexualmente na escola ou faculdade e 6\% em casa (DATAFOLHA, 2018).

O assédio vivido cotidianamente há décadas pelas mulheres é uma das temáticas abordadas pelo ciberfeminismo. A partir do uso de todos os recursos tecnológicos disponíveis, as mulheres passaram a ocupar o espaço virtual criando fóruns de debates, grupos nas redes sociais, publicações, 
compartilhamentos, memes, caricaturas, etc. Nosso objeto específico neste trabalho, refere-se à apropriação da hashtag pelo movimento ciberfeminista. A hashtag pode ser definida enquanto

[... ] segmento de linguagem precedido do símbolo \#, utilizado originalmente na rede Twitter, mas adaptado a outras plataformas, como o Facebook. Essa associação faz com que se torne uma tag clicável, inserida manualmente no Twitter que permite acessar um fio que reúne o conjunto dos enunciados que contém a hashtag [...] (PAVEAU, 2017, p. 196).

Nosso olhar, neste momento incidirá especialmente na reflexão sobre o funcionamento da hashtag como dispositivo tecnolinguageiro (PAVEAU, 2017) utilizado pelos movimentos sociais na internet. De acordo com a referida autora, "a hashtag é uma convenção criada pelos usuários da rede (KWAK et al. 2010). É uma forma tecnolinguageira cuja função é essencialmente social, permitindo afiliação difusa" (PAVEAU, 2017, p. 197).

A hashtag desempenha relevante papel no chamado ciberativismo e a tentativa de desenhar um percurso acerca dos usos desta ferramenta no ativismo feminista virtual permite refletir acerca do processo mais amplo de criação de uma forma reiterável, que pode ser utilizada por vários usuários e que, pode ainda, ser reformulada mantendo a mesma estrutura. A hashtag funda uma comunidade discursiva e delimita a defesa de determinada visão de mundo, na mesma medida em que se abre ao diálogo e à polêmica.

Ancorados, portanto, na Análise do discurso francesa pretendemos refletir acerca da criação, uso e circulação da hashtag enquanto dispositivo tecnolinguageiro (PAVEAU, 2017), abordando especificamente a \#metoo (\#eutambém, em português), que tomou conta da internet em outubro de 2017 acerca dos casos de assédio sexual sofridos por mulheres no seu ambiente de trabalho e em nas relações profissionais em Hollywood ${ }^{5}$.

Tendo tais questões no horizonte, salientamos que nosso interesse principal neste artigo foi enfatizado pela circulação mundial da hashtag \#metoo: em apenas dois dias ela foi usada mais de 200 mil vezes nas redes sociais $^{6}$. O alcance de tal hashtag tem relevância não apenas em relação à

\footnotetext{
${ }^{5}$ É importante assinalarmos que o feminismo é cada vez mais heterogêneo e plural e que muitas mulheres (asiáticas, negras e latinas, por exemplo) não se sentem representadas pelas hashtags que circulam na web. Além disso, é necessário, ainda, ter consciência de que a referida hashtag pode ter alcançado posição de destaque devido o fato de estar relacionada a atores sociais expostos pela mídia.

${ }^{6}$ Em reportagem sobre o tema, o site da BBC afirma, em 17/10/2017, que "A hashtag \#MeToo já foi usada mais de 200 mil vezes nas redes sociais". Ela havia sido primeiramente publicada dois dias
} 


\section{$\mathrm{EI} \square \mathrm{dA}$}

quantidade em que foi replicada nas redes, mas principalmente devido à visibilidade proporcionada à pauta mais ampla e complexa do próprio do movimento feminista: o assédio sofrido por mulheres, especialmente no ambiente de trabalho.

\section{Metodologia: a mobilização da memória discursiva do assédio}

Refletiremos cientificamente sobre o funcionamento discursivo da hashtag \#metoo ancorados no referencial teórico da Análise do discurso, contemplando especificamente as noções de memória e des-memória discursivas (PAVEAU, 2013) como mecanismos linguístico-discursivos engendrados na construção do sentido. A partir da mobilização da memória discursiva do assédio ou da tentativa de apagamento desta linhagem discursiva - ambas determinadas pela formações discursivas específicas - há a instauração da polêmica como interincompreensão (MAINGUENEAU, 2008).

A noção de memória discursiva foi amplamente trabalhada na Análise do discurso tanto francesa, quanto brasileira. Nosso ponto de observação está, neste texto específico, ancorado na perspectiva proposta pela pesquisadora francesa Marie-Anne Paveau (2013, 2013a; 2015; 2017), especificamente nas suas reflexões científicas em torno da abordagem da memória e da desmemória discursiva.

Apesar deste artigo dialogar diretamente com outros trabalhos especificamente ancorados no pensamento de Pêcheux (1999) e Courtine (1999) por exemplo, ou ainda nas pesquisas de Abrahão e Souza (2004) e Orlandi (2007) -, devido a extensão deste texto, tais referências não serão amplamente comentadas. Além disso, é importante salientar que o próprio tema da pesquisa estabelece diálogo com o projeto Mulheres em discurso. Lugares de enunciação e processos de subjetivação, coordenado pela Profa. Dra. Mónica Zoppi-Fontana.

Especificamente sobre o corpus da pesquisa, é posíivel observar que a \#metoo foi amplamente disseminada na web em decorrência das denúncias de assédio, feitas pela atriz americana Ashley Judd, contra o magnata do cinema Harvey Weinstein. As denúncias foram feitas na reportagem intitulada

antes. Disponível em: http://www.bbc.com/portuguese/internacional-41652306. Acesso em: 10 abr.2018). 
Harvey Weinstein pagou acusadores de assédio sexual por décadas ${ }^{7}$, publicada em 5 de outubro de 2017 na versão online do jornal The New York Times (NEW YORK TIMES, 2017).

Na referida reportagem é narrativizado o modus operandi dos episódios de assédio de Weinsteln: ele convidava as mulheres para um hotel e lá praticava os abusos. Muitas o acusaram de assédio, dentre elas uma funcionária temporária (que trabalhou apenas um dia na empresa) e uma assistente; mas a denúncia que alavancou os processos foi feita pela atriz americana Ashley Judd ${ }^{8}$.

No dia 15 de outubro, a \#metoo foi lançada pela atriz Alyssa Milano, que sugeriu em sua conta pessoal no Twitter, que os usuários empregassem tal hashtag para compartilhar suas próprias experiências de assédio. Tal sugestão foi feita como manifestação de apoio às denúncias de assédio em Hollywood que não pararam de crescer $^{9}$. A publicação fundadora da referida hashtag no Twitter de Milano enunciava o seguinte:

Se você foi assediada sexualmente ou agredida, escreva 'me too' em resposta a esse tweet - Me too - Sugerida por um amigo "se todas as mulheres que tenham sido sexualmente assediadas ou agredidas escrevessem 'Me too' como status, nós poderíamos dar às pessoas uma noção da magnitude do problema. ${ }^{10}$

As hashtags funcionam a partir da mobilização de uma memória discursiva, mais específica e atual - as denúncias que circularam na web em torno do casos de Hollywood - e uma memória discursiva mais ampla e histórica (a que mais nos interessa): o assédio sofrido pelas mulheres devido à

\footnotetext{
7 Tradução nossa do título original em língua inglesa: "Harvey Weinstein Paid Off Sexual Harassment Accusers for Decades".

${ }^{8}$ Para maiores informações, consultar a referida reportagem (link de acesso na nota de rodapé anterior). A título de exemplo, transcrevemos a seguir um trecho da reportagem: "Duas décadas atrás, o produtor de Hollywood Harvey Weinstein convidou Ashley Judd para o Peninsula Beverly Hills Hotel, para o que a jovem atriz esperava ser um café da manhã de negócios. Em vez disso, ele a mandou subir para seu quarto, onde apareceu com um roupão e perguntou se ele poderia massageá-la ou se ela poderia observá-lo tomar banho, ela relembra na entrevista: "Como eu poderia sair desse quarto o mais rápido possível sem perturbar Harvey Weinstein? Srta. Judd disse se lembrar desse pensamento" (New York Times, online, 5/10/2017 - tradução nossa do original em língua inglesa)

${ }^{9}$ No dia 10 de outubro de 2017 , o New York Times publica nova reportagem afirmando que as atrizes Gwyneth Paltrow e Angelina Jolie se juntaram nas acusações de assédio contra Harvey Weinstein (Disponível em: https://www.nytimes.com/2017/10/10/us/gwyneth-paltrow-angelina-jolieharveyweinstein.html?action=click\&contentCollection=U.S.\&module=RelatedCoverage\&region=En dOfArticle\&pgtype=article. Acesso em: 7 dez.2017).

${ }^{10}$ Tradução nossa do tweet em língua inglesa: “If you've been sexually harrased or assaulted write 'me too' as reply to this tweet. - Me too - Suggested by a friend: 'If all the women who hava been sexually harrassed or assaulted wrote 'Me too.' as a statua, we might give people a sense of the magnitude of the problem”.Twiiter @Alyssa_Milano, publicado 15/10/2017, 1:21 pm.
} 


\section{$\mathrm{EI} \square \mathrm{dA}$}

Revista Eletrônica de Estudos Integrados em Discurso e Argumentação, Ihéus, n. 18, abr.2019.

desigualdade de gêneros e a dominação masculina na sociedade (cf. Bourdieu, 2014).

A hashtag \#metoo pode ser compreendida enquanto acontecimento discursivo na medida em que instaura a relação entre "o passado, a memória e a história" (MAINGUENEAU; CHARAUDEAU, 2008, p. 29). Implicitamente ao enunciado da hashtag, "eu também" (\#metoo), que condensa: "eu também sofri assédio ou fui agredida", ou ainda "eu também apoio a causa", está a temática mais ampla do assédio sofrido pelas mulheres ao longo da história.

Ao escrever \#eutambém o enunciador inscreve seu discurso na memória discursiva do assédio, neste caso especificamente acerca dos abusos de poder sofrido pelas mulheres no ambiente de trabalho e/ou nas relações profissionais. A hashtag \#metoo produz um elo de memória na medida em que insere os discursos que a mobilizam no fio determinado pela história da temática do assédio.

As publicações das (dos) internautas em resposta ao primeiro tweet da atriz reiteram a memória discursiva do assédio e continua operando pela categorização do acontecimento de acordo com a linhagem discursiva do assédio. Tais publicações se alinham à memória discursiva do assédio consequentemente se colocam em posição de repúdio aos abusos cometidos em Hollywood - como é possível observar na Figura 1:

\section{Figura 1 - Tweets com as hashtags \#metoo \#eutambém}

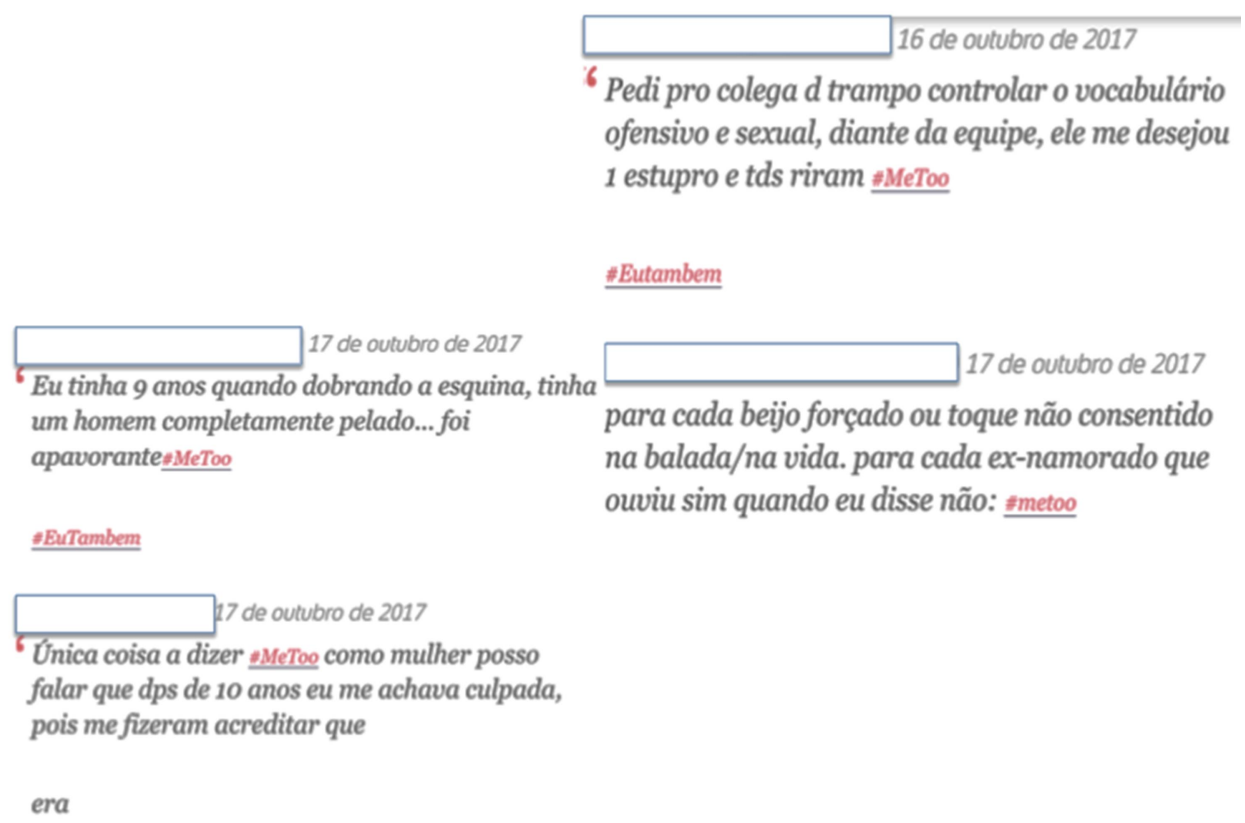

Fonte: Huffpost do Brasil, 2017 
Nas publicações é possível verificar a recorrência de semas como "assédio" e "abuso", os quais funcionam como pré-construídos no funcionamento da hashtag \#metoo. De acordo com Maingueneau e Charaudeau (2008, p. 401) "a noção de pré-construído está intimamente ligada à de interdiscurso", interdiscurso este, mobilizado pela recorrência à memória discursiva do assédio.

Compreedemos, neste trabalho, as noções de memória discursiva e de interdiscurso não como sinônimos, mas fenômenos que se entrecruzam, uma vez que a memória discursiva, "diz respeito à existência histórica do enunciado no seio de práticas discursivas reguladas pelos aparelhos ideológicos" (INDURSKY, 2011, p. 86), enquanto o interdiscurso se refere, a formulações que marcam diferentes enunciações articuladas linguisticamente por meio de citação, repetição e paráfrase (COURTINE, 1999). Ainda, de acordo com Paveau:

[... ] na perspectiva da cognição social, versão distribuída, coloco a natureza cognitivo-discursiva da memória no discurso. Isso implica renunciar às imagens estereotipadas da memória como simples armazenamento ou dicionário, para torná-la um agente ativo na produção de discursos. Se ela registra ou 'acumula' efetivamente os sentidos, a memória cognitivo-discursiva também elabora e constrói os sentidos, principalmente, pela operação de categorização (PAVEAU, 2013, p. 113-114).

A mobilização da memória discursiva do assédio pela disseminação da \#metoo \#meutambém foi empreendida pela própria mídia, que inseriu o debate suscitado pela referida hashtag na temática mais ampla do assédio sexual, de onde é possível inferir que a mídia operou a partir desta categorização semântica. Tal fato pode ser observado nos títulos de algumas reportagens publicadas à época: 'Eu também': A campanha global que chama atenção sobre a magnitude do assédio contra mulheres (HUFFPOST, 2017, grifos nossos); Milhares dizem 'eu também' a 'pesquisa' da atriz Alyssa Milano sobre assédio sexual ( $G 1,2017$, grifos nossos); \#EuTambém surge da impunidade e da cultura do silêncio em relação à violência sexual, diz ONU (ONUBR, 2017, grifos nossos) e \#EuTambém: Mulheres do mundo todo contam que sofreram assédio sexual (EL PAís, 2017, grifos nossos), dentre tantos outros.

A partir dos referidos títulos é possível observar a que a hashtag (\#metoo; \#eutambém) é incorporada à temática mais ampla, determinada pelas seguintes categorizações semânticas: "assédio contra mulheres", "assédio sexual" e "violência sexual", por exemplo. A categorização, que 
refere a memória discursiva à qual esses discursos se filiam, está posta pela tematização.

De acordo com Paveau (2013; 2017) situações discursivas semelhantes, como a reiteração da hashtag na internet, operam de acordo com a categorização, isto é, ao utilizar a \#metoo o sujeito insere seu discurso na temática do assédio, na mesma medida em que a ressignifica e promove sua circulação. A memória, de uma perspectiva cognitivo-discursiva participa, portanto, da produção do discurso:

[...] o trabalho da memória gera situações discursivas semelhantes, que permitem essa extensibilidade semântica das palavras e das fórmulas, aplicáveis a novas situações pelo único fato de que elas foram aplicadas a situações antigas. Essa forma de repetição, longe de ser estéril, é um modo de categorização da experiência nos discursos que se pode chamar de conhecimento por reconhecimento (PAVEAU, 2013, p. 115).

\section{A desmemória discursiva em foco}

Ainda de acordo com a pesquisadora "a memória no discurso não pode, com efeito, ser apresentada de forma idealista como um conjunto de itinerários harmoniosos e ela deve dar conta igualmente das rupturas, esquecimentos [...]" (PAVEAU, 2013, p. 119). Isto significa que ao mobilizar determinada memória discursiva, outros fenômenos são abandonados no fio do discurso. A fim de dar conta de tais fraturas, revisões e deslizamentos, Paveau (2013) propõe o conceito de des-memória:

[...] chamo de des-memória discursiva um conjunto de fenômenos de discursos que permitem a revisão das linhagens discursivas, isto é, transmissões semânticas cultural e socialmente asseguradas pelas ferramentas de tecnologia discursiva (as placas de rua, por exemplo). Essas revisões podem ser as mudanças semânticas, os neologismos semânticos, as redenominações, as reformulações etc. Em suma, um conjunto de fenômenos linguageiros que vão produzir efeitos transgressivos ou contra-intuitivos em um contexto em que reine um acordo semântico, histórico e até mesmo ético (PAVEAU, 2013, p. 157).

Do ponto de vista linguístico-discursivo as hashtags são encaradas enquanto marcadores rastreáveis, isto é, ao publicar a hashtag o sujeito se integra no debate mais amplo em relação à determinada pauta, que está encarnada na própria tecnopalavra ${ }^{11}$. Juntamente com o uso da hashtag na interação virtual, o sujeito procura demarcar seu posicionamento ideológico

\footnotetext{
11 “Le hashtag est un technomot (PAVEAU, 2013a) car il possède une nature composite: le segment est bien langagier (il s'agit de sigles, mots, expressions ou même des phrases entières) mais également cliquable, puisqu'il constitue un lien qui permet la création d'un fil (PAVEAU, 2017, p. 199).
} 
em torno do tema por ela estabelecido, ao mesmo tempo em que assinala seu pertencimento à determinada formação discursiva.

Assim como as próprias formações discursivas são permeáveis, a memória discursiva é atravessada também por des-memórias, isto é, por esquecimentos que fazem parte da constituição do discurso. Da perspectiva da formação discursiva que mobiliza a memória do assédio sexual alinhado ao patriarcado e à dominação masculina da sociedade, há também um processo de des-memória discursiva, quando outros enunciadores promovem o deslizamento do acontecimento discursivo fundado pela hashtag.

No processo discursivo de estabelecimento do debate público em torno da temática do assédio fundado pela hashtag \#metoo \#eutambém é possível observar a mobilização da des-memória discursiva na tentativa de reformulação do fio discursivo e temático estabelecido no qual a hashtag procurou se inserir no cenário social e passou a nele circular e ganhar sentido.

Em 9 de janeiro de 2018, um coletivo de 100 mulheres francesas, dentre elas a atriz Catherine Deneuve, publicou um manifesto intitulado "Nós defendemos a liberdade de importunar, indispensável à liberdade sexual"12. Neste manifesto as autoras inserem seu discurso no acontecimento discursivo fundado pela \#metoo, porém o fazem a partir da polarização, isto é, se posicionando de modo contrário, como é possível observar nos trechos a seguir:

Na verdade, o \#metoo provocou na imprensa e nas redes sociais uma campanha de denúncia e acusação pública de indivíduos que, sem que lhes tenha sido dada a oportunidade de responder ou de se defender, foram colocados exatamente no mesmo nível que os agressores sexuais. Essa febre [...], longe de ajudar as mulheres a conquistar sua autonomia, serve na verdade aos interesses dos inimigos da liberdade sexual. Como mulheres, não nos reconhecemos nesse feminismo que, para além da denúncia do abuso de poder, assume as feições do ódio contra os homens e a sexualidade. Nós acreditamos que a liberdade de dizer não a uma proposta sexual não existe sem a liberdade de importunar. $E$ consideramos que é preciso saber responder a essa liberdade de importunar de outra maneira que não seja se fechar no papel de presa (EL PAís, 2017a).

Ao estabelecer a temática do assédio alinhada a novos semas como "liberdade de importunar" e "liberdade sexual", o referido manifesto promove a recategorização deste fenômeno discursivo. Para além de se

\footnotetext{
12 Tradução nossa do original em língua francesa "Nous défendons une liberté d'importuner, indispensable à la liberté sexuelle". Disponível em https://www.lemonde.fr/idees/article/2018/01/09/nous-defendons-une-liberte-d-importunerindispensable-a-la-liberte-sexuelle_5239134_3232.html
} 
posicionar em relação de polarização ao fio discursivo determinado pela \#metoo, o manifesto se constrói a partir da des-memória, uma vez que a própria "memória, não é somente conservação e retransmissão, ela é também modificação, falsificação e disparição" (PAVEAU, 2013, p. 119).

Ao mobilizar determinada temática, como a do assédio sexual, a hashtag se instaura como ponto de passagem para que o sujeito se posicione. A \#metoo provocou a tomada de posição e tomou os variados contornos, estabelecidos a partir da posição enunciativa (e da formação discursiva) do sujeito que as mobilizava.

De um lado, o ciberfeminismo se apropriou da \#metoo \#eutambém \#balancetonporc (respectivamente em inglês, português e francês) como forma de denúncia não somente do assédio sofrido pela atriz hollywoodiana, mas como espaço de mobilização social do feminismo em rede a favor da maior equidade entre homens e mulheres e denúncia do patriarcado, que ainda assola a sociedade contemporânea. A partir da mobilização da memória discursiva do assédio, a hashtag provocou a ascensão deste tema no debate público.

Por outro lado, o manifesto das atrizes francesas procurou concretizar de modo diferente sua visão acerca da hashtag e da temática mais ampla por ela encarnada. A partir da "liberdade de importunar" e da "liberdade sexual" o manifesto mobilizou uma des-memória discursiva, na medida em que procurou rebatizar o uso da hashtag enquanto "febre" que "provocou na imprensa e nas redes sociais uma campanha de denúncia e acusação pública de indivíduos [...] sem que lhes tenha sido dada a oportunidade de responder ou de se defender" (EL PAís, 2017a).

A mobilização da memória ou da des-memória discursiva no fio do discurso funciona como fator de argumentação para cada posicionamento em relação ao tema determinado pelo assédio e pelo papel social da mulher. $\mathrm{Na}$ memória discursiva instaurada pela \#metoo temos a defesa de um sujeito que exerce pleno direito sobre seu corpo, ao passo que na des-memória discursiva promovida pelo Manifesto, é construída a imagem do sujeito (mulher/sujeito que sofre o assédio) como aquele que inibe o direito do Outro (assediador).

A polarização discursiva e ideológica em relação ao tema do assédio construída na relação entre os dois discursos - aquele que mobiliza a \#metoo e aquele que se opõe a ela - os quais, a partir da memória e des-memória 
discursivas erigem ainda uma visão específica acerca da imagem da mulher na sociedade.

Se nos discursos que se inscrevem na memória discursiva do assédio, mobilizando a \#metoo, as mulheres são vistas enquanto dotadas de voz de vontade própria para participar de uma mobilização social na internet lembremos a convocação que a hahstag faz para que mulheres compartilhem suas experiências -; no discurso do Manifesto ela é alçada à posição de inibidora do direito do Outro, "inimigas da liberdade sexual" e "justiceiras expeditivas" que "castigam homens":

Essa justiça expeditiva já fez suas vítimas, homens castigados no exercício de sua profissão, forçados a se demitir, etc., quando seu único erro foi ter tocado um joelho, tentado roubar um beijo, falar sobre coisas "íntimas" em um jantar profissional ou ter mandado mensagens com conotação sexual a uma mulher cuja atração não era recíproca (EL PAÍS, 2017a, grifos nossos).

\section{Memória, des-memória e polêmica}

De acordo com Maingueneau "o espaço discursivo é considerado como rede interação semântica, ele define um processo de interincompreensão generalizada, a própria condição de possibilidade das diversas posições enunciativas" (MAINGUENEAU, 2008, p. 99). Isto significa afirmar que cada enunciador enuncia de acordo com as regras de sua formação discursiva na mesma medida em que não compartilha os enunciados do Outro.

A polêmica se instaura, portanto, não só como controvérsia, mas como fenômeno mais geral resultante da relação entre duas formações discursivas que se ancoram em diferentes matrizes interdiscursivas e que concretizam seus temas de modos distintos e essa distinção funda a polêmica como interincompreensão, na medida em que é "a semântica dos discursos que comanda a maneira pela qual os discursos se polemizam" (MAINGUENEAU, 2008, p. 107).

A temática do assédio mobilizada pela \#metoo foi semantizada de variadas maneiras, se ancorando em diferentes memórias e des-memórias. $\mathrm{Na}$ mobilização da memória discursiva do assédio encarnada na hashtag, observamos o sujeito que toma o ambiente virtual como espaço de mobilização social e que se posiciona a favor da denúncia e do empoderamento, tendo, como consequência, uma imagem de mulher socialmente ativa. No Manifesto de Deneuve et al., há a mobilização da des- 


\section{$\mathrm{EI} \square \mathrm{dA}$}

Revista Eletrônica de Estudos Integrados em Discurso e Argumentação, Ilhéus, n. 18, abr.2019.

memória discursiva do assédio na tentativa de recategorização do acontecimento fundado pela hashtag a partir do tema da "liberdade sexual". Nele, a imagem de mulher é estabelecida de acordo com o Outro socialmente pleno, este sim dotado da "liberdade de importunar".

A mobilização social das hashtags que gera, do ponto de vista discursivo, uma polêmica como interincompreensão, re-insere o tema do assédio no debate público fazendo com que circule e solicite o posicionamento do sujeito social. Mobilizar então a memória ou a des-memória, neste processo, tanto revela determinado ponto de vista, quanto inscreve o discurso e o sujeito em determinada comunidade discursiva.

Além disso, cada posicionamento erige uma imagem de mulher - menos ou mais empoderada no cenário social. A polêmica gerada em torno da hashtag contribui, portanto, com o debate da agenda feminista, que procura cada vez mais se utilizar das ferramentas do ciberespaço para instigar o questionamento em torno da equidade entre os gêneros. Ademais, promove reflexão em torno significações que se constroem discursivamente em torno da figura da mulher e seu papel social, a partir de temas que englobam este paradigma, tal como o assédio.

\section{Fontes}

DATAFOLHA, Assédio sexual entre as mulheres. PO 81394229 e 30/11/2017. Disponível em:http://media.folha.uol.com.br/datafolha/2018/01/11/bfed1c72ccoeff5f76027203648 546c5bbe9923c.pdf. Acesso em: 31 out.2018.

EL PAÍS. \#EuTambém: Mulheres do mundo todo contam que sofreram assédio sexual. 2017. Disponível

em: https://brasil.elpais.com/brasil/2017/10/16/estilo/1508163687_006817.html. Acesso em: 31 out.2018.

. A íntegra do manifesto assinado por Catherine Deneuve. 2017a. Disponível em: $\quad$ https://brasil.elpais.com/brasil/2018/01/12/opinion/1515792486_891199.html. Acesso em: 31 out.2018.

NEW YORK TIMES. Harvey Weinstein Paid Off Sexual Harassment Accusers for Decades. 2017. Disponível em: https://www.nytimes.com/2017/10/05/us/harveyweinstein-harassment-allegations.html. Acesso em: 31 out.2018.

ONUBR. \#EuTambém surge da impunidade e da cultura do silêncio em relação à violência sexual, diz ONU. 2017. Disponível em: https://nacoesunidas.org/eutambem- 
$\mathrm{EI} \square \mathrm{\alpha} A$

Revista Eletrônica de Estudos Integrados em Discurso e Argumentação, Ilhéus, n. 18, abr.2019.

surge-da-impunidade-e-da-cultura-do-silencio-em-relacao-a-violencia-sexual-diz-onu/.

Acesso em: 31 out.2018.

G1. Milhares dizem 'eu também' a 'pesquisa' da atriz Alyssa Milano sobre assédio sexual. 2017. Disponível em: https://g1.globo.com/pop-arte/noticia/milhares-dizem-eutambem-a-pesquisa-da-atriz-alyssa-milano-sobre-assedio-sexual.ghtml. Acesso em: 31 out.2018.

HUFFPOST DO BRASIL. 'Eu também': A campanha global que chama atenção sobre a magnitude do assédio. 2017. Disponível em: https://www.huffpostbrasil.com/2017/10/17/eu-tambem-a-campanha-global-quechama-atencao-sobre-a-magnitude-do-assedio-contra-mulheres_a_23246002/. Acesso em: 31 out.2018.

\section{Referências}

BOURDIEU, Pierre. A dominação masculina. Rio de Janeiro: Bertrand Brasil, 2014

BRASIL, Decreto-Lei no 2.848, de 7 de dezembro de 1940 - Código Penal. Artigo 216-A, incluído pela Lei $n^{\circ} 10.224$, de 2001. Disponível em: https://www.jusbrasil.com.br/topicos/10611615/artigo-216-do-decreto-lei-n-2848-de-07de-dezembro-de-1940. Acesso em: 31 out.2018.

CASTELLS, Manuel. La galaxia Internet. Barcelona: Areté, 2001.

COLLADO, Ana. Martinez; NAVARRETE, Ana. Ciberfeminismo: também uma forma de ativismo. $2007 . \quad$ Disponível em: http://www.rizoma.net/interna.php?id=220\&secao=desbunde. Acesso em: 25 mai.2017.

COURTINE, Jean-Jacques. O chapéu de Clémentis. Observações sobre a memória e o esquecimento na enunciação do discurso político. In: INDURSKY, Freda; FERREIRA, Maria Cristina Leandro (Org.). Os múltiplos territórios da Análise do Discurso. Porto Alegre: Editora Sagra-Luzzato, 1999.

DEIBERT, Ronald. J. International plug'n play? Citizen activism, the Internet, and the global public policy. International Studies Perspectives, n. 1, p. 255-272, 2000.

FACURI, Cláudia de Oliveira. et al. Violência sexual: estudo descritivo sobre as vítimas e o atendimento em um serviço universitário de referência no Estado de São Paulo, Brasil. Cadernos de Saúde Pública, Rio de Janeiro, v. 29, n. 5, p. 889-898. 2013.

HARAWAY, Donna Manifesto ciborgue: ciência, tecnologia e feminismo-socialista no final do século XX. In: SILVA, Tomaz Tadeu da (Org. e trad.). Antropologia do ciborgue. Belo Horizonte: Autêntica, 2000. p. 37-129. 


\section{$\mathrm{El} D \mathrm{dA}$}

Revista Eletrônica de Estudos Integrados em Discurso e Argumentação, Ilhéus, n. 18, abr.2019.

HAWTHORNE, Susan; KLEIN, Renate. Cyberfeminism: connectivity, critique and creativity. Melbourne: Spinfex Press, 1999.

HIRATA, Helena. et al. (Org.). Dicionário crítico do feminismo. São Paulo: Editora UNESP, 2009.

INDURSKY, Freda. A memória na cena do discurso. In: INDURSKY, Freda; MITTMAN, Solange; FERREIRA, Maria Cristina Leandro. Memória e história na/da análise do discurso. Campinas: Mercado de Letras, 2011. p. 67-89.

LÉVY, Pierre. Cibercultura. Tradução: Carlos Irineu da Costa. São Paulo: 34, 1999.

ROMÃO, Lucília Maria Sousa. Nós, desconhecidos, na grande rede. Linguagem em (Dis)curso. Tubarão, v. 5, p. 71-91, 2004.

MAINGUNENEAU, Dominique. Gênese dos discursos. Tradução: Sírio Possenti. São Paulo: Parábola Editorial, 2008.

MAINGUENEAU, Dominique; CHARAUDEAU, Patrick. Dicionário de Análise do discurso. Coordenação da tradução: Fabiana Komseu. São Paulo: Contexto, 2008.

ORLANDI, Eni Puccinelli. As formas do silêncio no movimento dos sentidos. Campinas: Editora da Unicamp, 1997.

PAVEAU, Marie-Anne. Memória, des-memória, a-memória: quando o discurso volta-se para seu passado. Tradução: Jocilene Santana Prado e Eduardo Lopes Piris. EID\&A Revista Eletrônica de Estudos em Discurso e Argumentação, Ilhéus, n.5. p. 137-161. dez.2013.

. Os pré-discursos: sentido, memória e cognição. Tradução: Graciely Costa e Débora Massman. Revisão da tradução: José Horta Nunes. Campinas: Pontes Editores, 2013a.

. Linguagem e Moral: uma ética das virtudes discursivas. Tradução: Ivone Benedetti. Campinas: Editora da Unicamp, 2015.

. L'Analyse du discours numérique. Dictionnaire des formes et des pratiques. Paris: Hermann, 2017.

PÊCHEUX, Michel. Papel da Memória. In: Papel da Memória. ACHARD, Paul et al. Tradução: José Horta Nunes. Campinas: Pontes, 1999.

PLANT, Sadie. Cyberfeminist simulations. In: STARRS, Josephine; PIERCE, Julianne; RIMINI, Francesca da; BARRATT, Virginia. Cyberfeminist Manifesto for the 21e Century. VNS Matrix, 1991.

RAGO, Margareth. Trabalho feminino e sexualidade. In: DEL PRIORE, Mary (Org.). História das mulheres no Brasil. São Paulo: Contexto, 1997. p. 578-606. 
RIGITANO, Maria Eugência Cavalcanti. Redes e ciberativismo: notas para uma análise do centro de mídia independente. BOOC - Biblioteca online de ciências da comunicação. 2003. Disponível em: http://www.bocc.ubi.pt/_esp/autor.php?codautor=890\#topo. Acesso em: 04 out.2018.

SANTAELLA, Lucia. Pós-humano. Por quê? Revista USP, São Paulo, n. 74, p. 126-137, jun./ago.2007.

Forma de citação sugerida

COSTA, Julia Lourenço. Memória e des-memória discursivas no movimento ciberfeminista. EID\&A - Revista Eletrônica de Estudos Integrados em Discurso e Argumentação, Ilhéus, n. 18, p. 38-56, abr.2019. DOI dx.doi.org/10.17648/eidea-182196. 